\title{
Qualitative and quantitative examination of bacosides and calcium in calcium enriched herbal ice cream by HPLC and AAS
}

\author{
MD Baig, M Dharani Kumar, AK Beena, SN Rajakumar and KA Gopalakrishnan
}

Received: 16 May 2018 / Accepted: 29 October 2018 / Published online: 21 February 2019

(C) Indian Dairy Association (India) 2019

\begin{abstract}
Bacopa monniera (B.monniera) plant has been reported as nerve tonic and memory enhancer from ancient times in Indian system of medicine i.e. Ayurveda. The active components present in B.monniera are Bacoside-A \& Bacopaside-II which are mainly responsible for its memory effects and other health benefits. Calcium gluconate $(\mathrm{CG})$, organic calcium having available calcium (13\%) is one of best sources for calcium fortification in ice cream. In this study, B.monniera extract $10 \mathrm{mg} / 100 \mathrm{~g}$ (Ethanol extraction) and calcium gluconate $217 \mathrm{mg} / 100 \mathrm{~g}$ was added to ice cream mix subjecting to ageing, freezing, hardening and storage. Sensory and physico-chemical analysis of the prepared product was carried out. HPLC analysis was carried out to confirm the presence of bacosides (BacosideA \& Bacopaside-II) and to estimate the quantity of bacosides. Calcium content in fortified ice cream was $165 \mathrm{mg} / 100 \mathrm{~g}$ where as control ice cream was $145 \mathrm{mg} / 100 \mathrm{~g}$.
\end{abstract}

Keywords: Bacopa monniera, Calcium gluconate, Physicochemical analysis, HPLC, AAS

\footnotetext{
MD Baig $(\bowtie)$

Department of Dairy Technology, College of Dairy science and Technology, KVASU, Kerala, 680651, India

E-mail: davuddinmohammed@gmail.com

M Dharani

Department of Dairy Technology, College of Dairy science and Technology, KVASU, Kerala, 680651, India

AK Beena

Department of Dairy Microbiology, College of Dairy science and Technology, KVASU, Kerala, 68065, India

SN Rajakumar

Department of Dairy Technology, College of Dairy science and Technology, KVASU, Kerala, 680651, India

KA Gopalakrishnan

Department of Veterinary Pharmacology and Toxicology, KVASU, Kerala, 68065, India
}

\section{Introduction}

Now a days, consumers are becoming health conscious and the demand for health foods has been increasing. There has been a considerable interest in extending the use of herbs in dairy foods, fruits juice based products and pharmaceuticals (Singh, 2010). Herbal ice cream is gaining popularity over normal ice cream due to its functional, nutritional and pharmacological activities. Ice cream is a commonly enjoyed palatable food product that provides a useful source of dietary calcium and can be fortified to supply additional amounts without changing its flavour and colour (Rungrat et al., 2017). Fortification can be done with commercially available calcium salts like calcium gluconate, calcium carbonate, calcium chloride, calcium phosphate, calcium lactate and natural milk calcium (Davis, 2002). Calcium, an important mineral component of human diet is chiefly available in milk and milk products, seafood, legumes and some vegetables. Adequate calcium intake has been associated with reduced risk of osteoporosis, hypertension, colon cancer, kidney stones (Bhatia, 2008). Over the past years, economic burden of osteoporosis is increasing and the clinical implications of calcium deficiency are being better recognized. For the above stated reasons, a reconsideration of dietary calcium intake through calcium fortified foods is needed. Calcium from dairy products is easily absorbed by intestine due to favourable effect of casein on calcium absorption by inhibiting calcium precipitation by phosphate in intestinal lumen through the action of phosphopeptides coming from enzymatic hydrolysis of casein (Kaushik et al., 2015). Due to the above fact calcium from dairy products has higher bioavailability than calcium in vegetables or cereals and further can be fortified with calcium salts in order to meet required daily intake or to reduce calcium deficiency diseases such as osteoporosis, osteomalacia, hypertension, colon cancer and obesity (Gerstner, 2003). As ice cream is most popular dairy product which is widely accepted among different age groups choosen as vehicle for fortification. Bacopa monniera (B.monniera) or Brahmi is an ayurvedic medicine, clinically used for memory enhancing and as nerve tonic in Indian traditional medicine (Chopra et al., 1969). The plant had been used as a nootropic, digestive aid and to improve learning, memory and respiratory functions (Nadkarni, 1988). The activities of Bacopa monniera are believed to be associated with the polar fraction, 
mainly containing saponins as a complex mixture of Bacoside-A, Bacoside B \& Bacoside C and pseudojujubogenin glycosides Bacopaside I \& Bacopaside II (Rastogi et al., 1994; chakravarthy et al., 2001). In humans, B.monniera showed improved early information processing, verbal learning and memory consolidation (Stough et al., 2001). The safety of doses of extracted bacosides has been tested in healthy male human volunteers $100 \mathrm{mg}$ bacosides orally for 4 weeks didn't reveal any drug related abnormality (Singh and Dhawan 1997), B.monniera is currently recognised as effective in treatment in mental illness and epilepsy. Herbs like B.monniera can be incorporated into ice cream for value addition and health benefits. Without saponins, the amount of calcium absorbed ranges from $5.8 \%$ in $15 \mathrm{~min}$ to $18 \%$ in $100 \mathrm{~min}$. On addition of saponins the amount of calcium absorbed increased $13 \%$ in $15 \mathrm{~min} \& 36.5 \%$ in $100 \mathrm{~min}$ (Singh, 2008). High Performance Liquid Chromatography (HPLC) (Haratifar et al., 2014) and methods based on UV detection have been developed for the determination of bacosides in $\mathrm{B}$. monniera (Shrikumar et al., 2004). Flame Atomic Absorption Spectrometry (FAAS), Graphite Furnace Atomic Absorption Spectrometry (GF AAS), and Inductively Coupled Plasma Optical Emission Spectrometry (ICP OES) are the main techniques used for the determination of trace element contents in food analysis laboratories. In the present study calcium enriched herbal ice cream was prepared with B.monniera extract (ethanol extraction) and calcium gluconate (CG) with following objectives. To assess the physico-chemical properties of prepared ice cream. To estimate bacosides and calcium content from prepared ice cream sample by HPLC and FAAS methods.

\section{Materials and methods}

Soxhlet extractor (Rotek equipments pvt.ltd, 1992, Canada)

Rotary flash evaporator (Hahnshin, Model-HS-2005V-N)

Freeze dryer (Operon, Model-FDU7003).

Batch freezer (Technogel, Model- M20)

Atomic absorption spectroscopy (Perkin Elmer, Model-PinAAcle 900H)

\section{HPLC (Dionex softron, Model-RSLC)}

\section{Extraction of active components of $B$.monniera whole plant}

Fresh B.monniera plants were purchased from local market. They cleaned with $20 \%$ solution of tween deionised water. Cleaned plants were then sun dried for $72 \mathrm{~h}$. Further moisture was removed in a hot-air oven at $50{ }^{\circ} \mathrm{C}$ for $4 \mathrm{~h}$. The dried plant material was coarsely powdered and stored in air tight container at room temperature. 900 grams of finely ground B.monniera plant powder was kept in a 'thimble' of soxhlet chamber and soaked in sufficient ethanol. Distillation flask attached to the end of soxhlet chamber was filled with ethanol (solvent) to $3 / 4^{\text {th }}$ of the volume. Distillation process to extract bacosides was carried for $72 \mathrm{~h}$ until a clear ethanol solution was visible in chamber. The collected distillate was filtered initially with muslin cloth and then with whatman paper (no $1,11 \mu \mathrm{m}$ pore size). Filtered distillate obtained so removed by using rotary flash evaporator at a temperature of $45^{\circ} \mathrm{C}$ and pressure of distillation at 55 bar. Further removal of residual ethanol from concentrated plant material was done by keeping in hot air oven at $50^{\circ} \mathrm{C} / 48 \mathrm{~h}$. The concentrated material was freeze dried at a condenser temperature of $-70^{\mathrm{R}} \mathrm{C}$ at a pressure of 50-100 $\mathrm{mm}$ torr. The freeze dried material was packed in air tight container and stored at $-4^{\circ} \mathrm{C}$.

\section{Experimental design to optimize levels of CG and active components of B.monniera}

The response surface methodology (Design expert ${ }^{\circledR}$ software version 9.0.4.1) was used to design the experiment based on a Central Composite Rotatable Design (CCRD) for the optimization of different levels of CG and dried active components of B.monniera in the formulation of experimental ice cream. The optimization of the level of factors was carried out based on the sensory characteristics such as colour, flavour, body and texture, melting property and overall acceptability. Thirteen sets of experiments were performed by taking different levels of factors. The centre point experiment was repeated six times to calculate reproducibility of the method.

\section{Preparation of experimental ice cream}

Skim milk ( $0.5 \%$ Fat, $8.7 \%$ SNF) and cream ( $40 \%$ Fat, $5.4 \%$ SNF) was taken and subjected to pasteurization $\left(80^{\circ} \mathrm{C} / 25 \mathrm{sec}\right)$. It was cooled to $60^{\circ} \mathrm{C}$ and dry ingredients including CG $(217 \mathrm{mg} / 100 \mathrm{~g}$ ice cream mix), sugar (15\%), stabilizers/emulsifiers ( $0.5 \%)$ and powder containing active components of B.monniera extract $(10 \mathrm{mg} / 100 \mathrm{~g}$ ice cream mix) were added to ice cream mix. Thorough mixing of ice cream mix was done and then subjected to two stage homogenization at $60^{\circ} \mathrm{C}(13.8 \mathrm{MPa}$ and $3.45 \mathrm{MPa})$. After homogenization, ice cream mix was kept for ageing at $4^{\circ} \mathrm{C} / 24 \mathrm{~h}$. By using batch freezer ice cream mix was frozen and incorporated with air at $-4^{\circ} \mathrm{C} / 7 \mathrm{~min}$. The product obtained was filled in polystyrene cups and placed in hardening room for hardening ($24^{\circ} \mathrm{C} / 6 \mathrm{~h}$ ). Finally the product was taken from hardening room and stored in a freezer at $-15^{\circ} \mathrm{C}$.

\section{Chemical and Physical analysis}

Ice cream samples were analysed for fat, solids non fat (SNF), total solids (TS), $\mathrm{pH}$ and titratable acidity according to AOAC international (2000) methods. Overrun was calculated by using formula given by Marshall et al. (2003). Water activity of ice cream sample was determined using water activity meter (Novasina swift, Model: labstar) as described by Konar (2013).

\section{Bacoside analysis in experimental ice cream by using HPLC}


The experimental ice cream was evaluated for quantitative and qualitative analysis by using HPLC at Central Instrumentation Laboratory, Kerala Veterinary and Animal Sciences University (KVASU), Kerala.

\section{Sample preparation of reference standard}

Reference standard (mixture of Bacoside- $\mathrm{A}_{3}$ Bacopaside-II, Jujubogenin isomer of Bacopasaponin C \& Bacopasaponin C) was procured from Natural Remedies Private Limited, Bangalore. Six dilutions were made from reference standard sample in a range 0.5 to $20 \mathrm{mg}$ dissolved of methanol and filtered through a $0.45 \mu \mathrm{m}$ PVDF filter prior to injection into chromatographic system.

\section{Sample preparation of ice cream}

$10 \mathrm{~g}$ of melted experimental ice cream taken in $125 \mathrm{ml}$ conical flask and $100 \mathrm{ml} \mathrm{PBS} \mathrm{(Phosphate-} \mathrm{buffered} \mathrm{saline)} \mathrm{at} 7.4 \mathrm{pH}$ was added. Absolute ethanol $(15 \mathrm{ml})$ was added and centrifuged $(5000 \mathrm{rpm} /$ $5 \mathrm{~min})$ at $5^{\circ} \mathrm{C}$. After centrifugation supernant was removed and repeated two more times to make a clear sample free from fat and protein. The ice cream sample was filtered through a $0.45 \mu \mathrm{m}$ PVDF filter prior to injection into chromatographic system.

\section{HPLC analysis}

The separation was performed using a HPLC system equipped with a photodiode array detector (PDA), an LC-10ATVP pump (Dinoex softron,Germany) and a Rheodyne injector with $1 \mu \mathrm{L}$ loop. Acclaim ${ }^{\mathrm{TM}} 120$ column-18 (150x2.1mm, $3 \mu \mathrm{m}$ particle size $)$ was used together with a Phenomenex RP-18 guard column. The mobile phase consisted of HPLC grade water and acetonitrile $(65: 35 \mathrm{v} / \mathrm{v})$. The flow rate and total run time were $1.0 \mathrm{ml} / \mathrm{min}$ and $40 \mathrm{~min}$, respectively. All peaks were integrated at the wavelength of $205 \mathrm{~nm}$ and results were interpreted. Analysis of samples involves running the reference standard sample first where peak areas and retention times were noted down (Fig 1). Following B.monniera extract \& ice cream sample were made to run and same peak areas and retention times noted down (Fig 2). B.monniera saponins (Bacosides) can only be detected at wavelength of $205 \mathrm{~nm}$. The identification of the bacosides was confirmed by comparing the retention times of standard compound to the B.monniera extract and ice cream sample. Calibration curves were generated by linear regression based on the peak areas (mAU) on $\mathrm{Y}$ axis and concentration $(\mathrm{mg} / \mathrm{mL})$ on X axis. The linearity was obtained within the range of injected concentrations $(0.5-20 \mathrm{mg})$. Based on calibration curve, regression equation was generated for calculation of each bacoside. Linearity with high squares of correlation coefficient $\left(\mathrm{R}^{2}=0.9999\right)$ were obtained for reference standard.

\section{Estimation of calcium content in ice cream samples by AAS}

$217 \mathrm{mg}$ of CG was added to $100 \mathrm{~g}$ ice cream mix. The amount of available calcium present in CG salt was calculated by

$$
\begin{aligned}
\text { Available calcium }(X) & =\frac{\text { MW of calcium }}{\text { MW of calcium gluconate }} \times C G(x) \\
& =\frac{40}{448.31} \times 217=19.36 \mathrm{mg} / 100 \mathrm{~g}
\end{aligned}
$$

MW $=$ Molecular Weight, $\mathrm{X}=$ amount of available calcium present in $\mathrm{CG}$

$\mathrm{x}=$ amount of $\mathrm{CG}$ added

Calcium content in ice cream was estimated by using Atomic Absorption Spectroscopy (Perkin Elmer, Model-PinAAcle 900H) according to IS: 12760:2012. Ice cream samples were subjected to dry digestion before aspirated in to the flame of AAS. For calcium estimation in AAS air acetylene flame was used.

\section{Preparation of standard solution}

$1.269 \mathrm{~g}$ calcium carbonate $(99.9 \%$ ) was mixed with $20 \mathrm{ml}$ water and $20 \mathrm{ml}$ concentrated $\mathrm{HNO} 3$ was added to it and the volume made up to $250 \mathrm{~mL}$ with water. Standard calcium solution was used to prepare dilutions of 1, 2, 5 and 8 ppm concentrations of calcium carbonate. Each solution was aspirated into the flame of the AAS and its absorbance was measured.

\section{Sample preparation for AAS analysis}

One $\mathrm{ml}$ of melted ice cream of both control and experimental was taken in silica crucibles followed by heating on hot plate to complete charring. The charred samples were incinerated in a muffle furnace at $550{ }^{\circ} \mathrm{C}$ for $3-4 \mathrm{~h}$ till white ash was obtained. The samples were cooled in a desiccator to room temperature and 1 $\mathrm{ml}$ concentrated nitric acid was added to dissolve the ash, contents were then transferred to $25 \mathrm{ml}$ volumetric flask and volume was made up to dilution so that the concentration falls within the range of standard solutions concentration. Both control and experimental samples were replicated 5 times and data was expressed as mean values with standard errors.

\section{Statistical analysis}

For all standardized values of responses, analysis of variance (ANOVA) and multiple regression analysis were conducted using Design Expert - version 9.0.4.1 (Statease Inc., Minneapolis, USA) to examine statistical significance of model terms. The nonsignificant terms were deleted by the backward elimination regression and the polynomial was recalculated. The adequacy of developed models were determined using $F$ values, lack-of fit test, $\mathrm{R}^{2}$ (coefficient of determination), Coefficient of variation (CV), Predicted Residual Error and Sum of Squares (PRESS) and Adequate Precision Ratio (APR). Three dimensional response surfaces are generated using Design Expert - version 9.0.4.1. The numerical and graphical optimization was also performed by the same software. 


\section{Results and discussion}

\section{Chemical and physical analysis}

The chemical composition, water activity, calcium and overrun of experimental ice cream were compared to that of control ice cream by using independent $t$ test and were presented in Table 1 . Fat, TS, Sugar, Titratable acidity, $\mathrm{pH}$, water activity and overrun of freshly prepared experimental ice cream had shown no significant difference $(\mathrm{p}>0.05)$ compared to control ice cream. Addition of $\mathrm{CG}$ and dried powder containing active components of B.monniera had no negative effect on chemical and physical properties of ice cream. Similar findings were reported by Costa et al. (2008) that calcium chloride addition in ice cream mix had no signiûcant effect $(\mathrm{p}>0.05)$ on fat and total solids of ice cream.

The water activity content of experimental ice cream and control ice cream had shown significant difference $(\mathrm{p}<0.05)$. Water activity of 7 days stored ice cream had shown lower water activity (0.957) compared to control ice cream (0.967). This may be because of calcium mineral has potential to hold free water and thus decreases water activity in food products. Similar results were reported by Singh et al.(2008) that calcium lactate fortified yoghurt shown significant increase in the water holding capacity ( $2.9 \%)$ on $1^{\text {st }}$ day of storage and shown significant decrease in water activity as compared to the control $(P<0.01)$.

\section{Estimation of calcium content in ice cream samples by AAS}

$19.3 \mathrm{mg} / 100 \mathrm{~g}$ available calcium was fortified through CG of 217 $\mathrm{mg} / 100 \mathrm{~g}$. Calcium in control ice cream was $145 \mathrm{mg} / 100 \mathrm{~g}$ while in experimental ice cream was $160 \mathrm{mg} / 100 \mathrm{~g}$. As calcium was fortified in ice cream there was a significant difference between control and experimental ice cream.

\section{Estimation of bacosides in experimental ice cream using HPLC}

Table 1. chemical composition, water activity $\left(\mathrm{a}_{\mathrm{w}}\right)$ and overrun of experimental ice cream

\begin{tabular}{lllc}
\hline Attributes & Experimental ice cream & Control ice cream & t-value \\
\hline Fat $(\%)$ & $10.33 \pm 0.09$ & $10.26 \pm 0.10$ & $0.42^{\text {ns }}$ \\
Total solids $(\%)$ & $36.76 \pm 0.19$ & $36.31 \pm 0.12$ & $1.49^{\text {ns }}$ \\
Sugar $(\%)$ & $15.05 \pm 0.21$ & $15.06 \pm 0.28$ & $0.17^{\text {ns }}$ \\
pH & $7.19 \pm 0.13$ & $7.19 \pm 0.04$ & $0.41^{\text {ns }}$ \\
Titratable acidity $(\% L A)$ & $0.18 \pm 0.04$ & $0.18 \pm 0.01$ & $0.30^{\text {ns }}$ \\
Water activity $\left(\mathrm{a}_{\mathrm{w}}\right)$ & $0.942 \pm 0.002$ & $0.967 \pm 0.006$ & $2.75^{*}$ \\
Overrun $(\%)$ & $55.20 \pm 0.96$ & $54.40 \pm 1.46$ & $0.393^{\text {ns }}$ \\
Calcium $(\mathrm{ppm})$ & $364.66 \pm 4.17$ & $145.50 \pm 1.78$ & $35.02^{* *}$ \\
\hline
\end{tabular}

Figures are the Mean \pm Standard Error of six replications, ${ }^{*}$-Significant at five per cent level $(\mathrm{p}<0.05),{ }^{* *}$-Significant at one per cent level ( $\mathrm{p}<0.01)$, ns- non-significant $(\mathrm{p}>0.05)$

Table 2: Peak area and retention times of reference sample with replicate injections

\begin{tabular}{|c|c|c|c|c|c|}
\hline \multirow[t]{2}{*}{$\overline{\text { Sl no }}$} & \multicolumn{2}{|c|}{$\begin{array}{l}\text { Standard dilution of } \\
\text { reference sample }(\mathrm{mg} / \mathrm{mL})\end{array}$} & \multicolumn{2}{|c|}{$\begin{array}{l}\text { Peak area } \\
(\mathrm{mAU}) \text { at } 205 \mathrm{~nm}\end{array}$} & $\begin{array}{l}\text { Retention } \\
\text { time (min) }\end{array}$ \\
\hline & & Bacoside-A & Bacopaside- II & Bacoside-A & Bacopaside-II \\
\hline 1 & 0.5 & 0.16 & 0.02 & 32.237 & 34.877 \\
\hline 2 & 1.0 & 0.29 & 0.14 & 31.773 & 34.833 \\
\hline 3 & 5.0 & 1.00 & 1.54 & 31.873 & 34.517 \\
\hline 4 & 10 & 1.92 & 3.27 & 31.356 & 34.256 \\
\hline 5 & 15 & 2.83 & 5.0 & 30.564 & 33.545 \\
\hline 6 & 20 & 3.75 & 6.74 & 30.145 & 33.24 \\
\hline Average & 8.58 & 1.65 & 2.77 & 31.32 & 34.21 \\
\hline Std.dev & 8.28 & 1.43 & 2.72 & 0.81 & 0.68 \\
\hline$\%$ RSD & 91.61 & 86.83 & 98.28 & 2.59 & 1.98 \\
\hline
\end{tabular}

Table 3. Peak area and retention times of standard dilution of ice cream samples

\begin{tabular}{|c|c|c|c|c|c|c|}
\hline \multirow[t]{2}{*}{ S No. } & \multirow[t]{2}{*}{ Sample } & \multirow{2}{*}{$\begin{array}{l}\text { Standard } \\
\text { dilution } \\
(\mathrm{mg} / 50 \mathrm{ml})\end{array}$} & \multirow{2}{*}{\multicolumn{2}{|c|}{$\begin{array}{l}\text { Peak area (mAU) } \\
\text { in ice cream at } 205 \mathrm{~nm}\end{array}$}} & \multicolumn{2}{|r|}{$\begin{array}{l}\text { Retention } \\
\text { time (min) of ice cream }\end{array}$} \\
\hline & & & & & Bacoside -A & Bacopaside -II \\
\hline$\overline{1}$ & Ice cream & 50 & 3.67 & 6.41 & 30.383 & 32.88 \\
\hline
\end{tabular}


Fig 1. Chromatogram of bacosides for reference standard

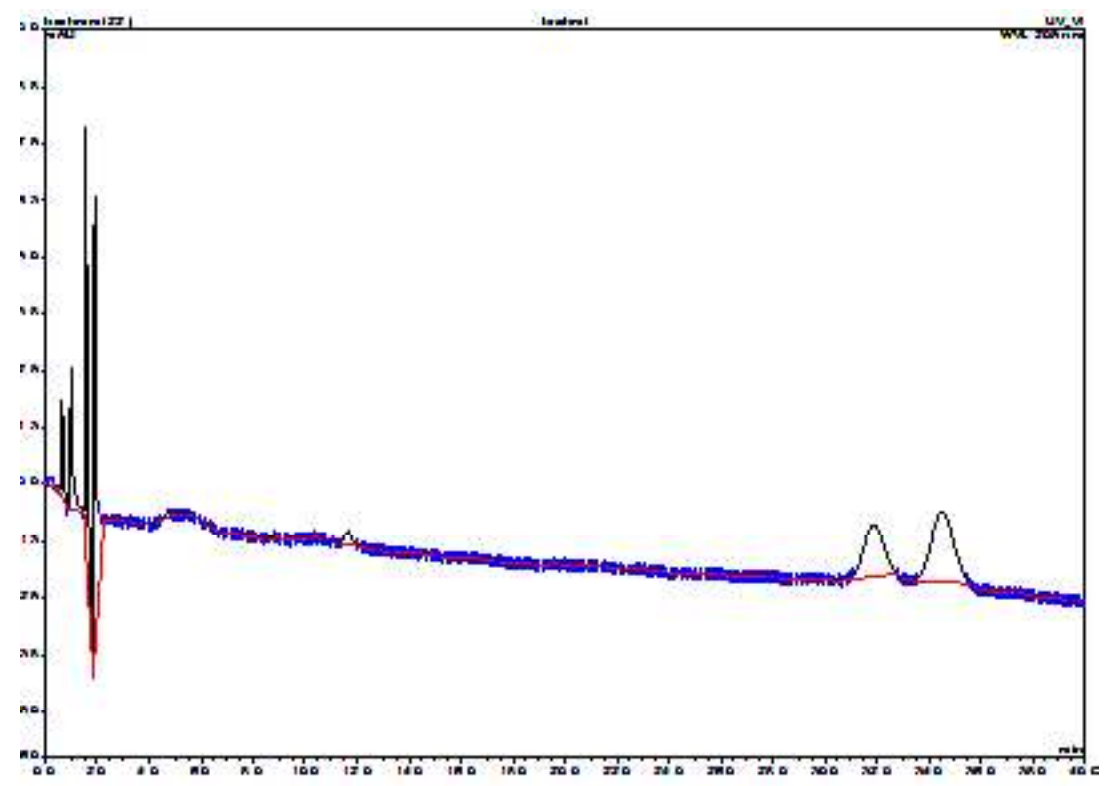

Fig 2. Chromatogram of bacosides for Ice cream sample

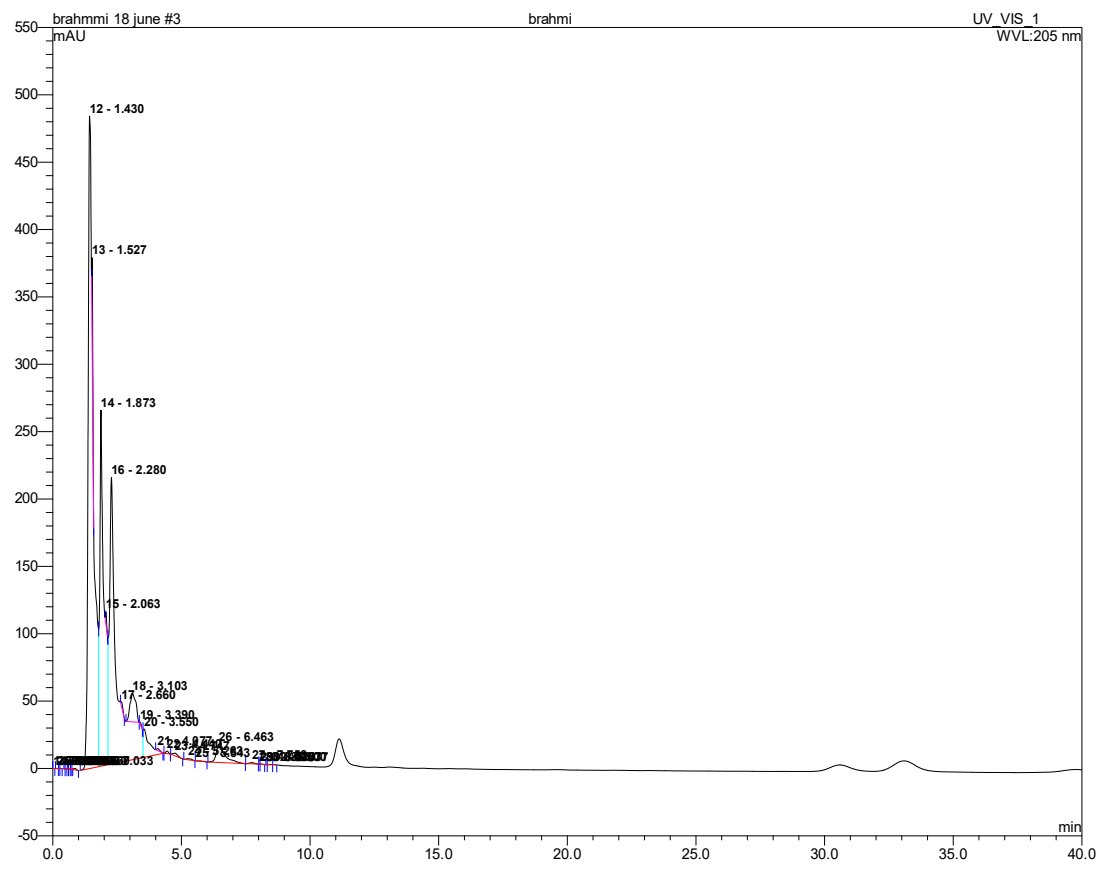

Table 4. Equations and good of fitness $\left(\mathrm{r}^{2}\right)$ obtained from calibration curves of the analyses of bacosides using HPLC

\begin{tabular}{llll}
\hline Sample & Component & Equation & $\mathrm{R}^{2}$ \\
\hline Ice cream & Bacoside-A & $\mathrm{Y}=0.0911+0.1826 \mathrm{X}$ & 0.9999 \\
& Bacopaside-II & $\mathrm{Y}=0.34690 \mathrm{X}-0.2006$ & 0.9997
\end{tabular}

Ice cream sample was analysed for the identification of bacosides present and amount of bacosides was quantified. Qualitative analysis was done by comparing the retention times of compounds at which they are eluted as peaks having highest purity (Fig $1 \& 2)$. Retention times of compounds of reference standard and ice cream sample were presented in Table $2 \& 3$. Amount of bacosides were calculated with the help of calibration curve and regression equation. Similarly ice cream sample was analysed accordingly and found total bacoside content $0.36 \mathrm{mg} / 100 \mathrm{ml}$ in 
which Bacoside A is $0.19 \mathrm{mg} / 100 \mathrm{ml}$ and Bacopaside II is $0.17 \mathrm{mg} /$ $100 \mathrm{ml}$.

\section{Conclusions}

Addition of CG and B.monniera did not affect the $\mathrm{pH}$ and TA of ice cream sample. Addition of $C G$ had increased the calcium content of ice cream from $145 \mathrm{mg} / 100 \mathrm{~g}$ to $165 \mathrm{mg} / 100 \mathrm{~g}$. The daily intake of calcium recommended by Indian council of medical research (ICMR) for children and adults are 600 and $1000 \mathrm{mg} /$ day. Therefore by addition of CG it may reach to required daily intake suggested by ICMR. Presence of calcium in ice cream had a tendency to water holding resulting in lower activity. As experimental ice cream is having total bacoside content $0.36 \mathrm{mg} /$ $100 \mathrm{ml}$ in which Bacoside A is $0.19 \mathrm{mg} / 100 \mathrm{ml}$ and Bacopaside II is $0.17 \mathrm{mg} / 100 \mathrm{ml}$. Consuming B.monniera from experimental ice cream may have its affect on memory of children at their growing stages.

\section{Acknowledgments}

The authors thank the "College of Dairy Science and Technology" (CDST, Kerala, India) for the financial support to carryout research and "Department of Veterinary Pharmacology and Toxicology" (COVAS, Kerala) for their support in extraction of Bacopa monniera plant.

\section{References}

AOAC (2000) Official Methods of Analysis. (17th ed). AOAC International, Gaithersburg, MD. 58pp.

Bhatia V (2008) Dietary calcium intake - a critical reappraisal. Indian J Med Res 127: 269-273

Chopra RN, Chopra IC, Verma BS (1969) Glossary of Indian medicinal plants.CSIR, New Delhi. 10p

Costa FF, Resende, JV, Abreu LR, Goff HD (2008) Effect of calcium chloride addition on ice cream structure and quality. J Dairy Sci 91: 2165-2174
Davis J (2002) Calcium. Functional food and nutraceuticals. [Online] 6: $15 . \quad$ Available:/http://www.ffnmag.com/ASP/ articleDisplay.asp?strArticleId. [12 Jun 2006]

Gerstner G (2002) Dairy products: The calcium challenge. Int Food Ingredients 3: 45-48

IS: 12760 (2012) Determination of calcium, sodium, potassium and magnesium content- Atomic Absorption Spectrometric method. Manak Bhavan, 9- Bahadur Shah Zafar Marg, New Delhi - 1

Konar N (2013) Influence of conching temperature and some bulk sweetners on physical and rheological properties of prebiotic milk chocolate containing inulin. Eur Food Res Technol. 236: 135-143

Kumar S, Rai DC, Singh D (2013) Role of herbal ice cream in human health A Review. Trends in Biosci 6(2): 130-132

Marshall TR, Goff HD (2003) In: Hartel RW (ed) Ice cream, $6^{\text {th }}$ edn. Springer Science Business Media, New York 233p

Nadkarni KM (1988) The Indian Materia Medica Columbia, MO: South Asia Books, pp. 624-25

Phrompittayarat W, Wittaya-areekul S, Jetiyanon K, Putalun W, Tanaka H, Ingkaninan K (2007) Determination of saponin glycosides in Bacopa monnieri by reversed phase High Performance Liquid Chromatography. Thai Pharma Hlth Sci J 2: 1

Rastogi S, Pal R, Kulshreshtha, DK (1994) Bacoside A3-a triterpenoid saponin from Bacopa monniera. Phytochem 36:133-7

Shrikumar S, Sandeep S, Ravi TK, Umamaheswari M (2004) A HPTLC Determination and fingerprinting of Bacoside A in Bacopa monniera and its formulation. Indian J Pharm Sci 66: 132 - 135

Singh D (2010) Efficacy of herbal extract on micro flora of probiotic frozen yoghurt. M.Tech Dissertation, Allahabad Agricultural Institute-Deemed University, Allahabad, $64 \mathrm{p}$

Singh G, Muthukumarappan K (2008) Influence of calcium fortification on sensory, physical and rheological characteristics of yoghurt. Food Sci Technol 41: 1145-1152

Soni S (2009) The story of Ice-cream. Indian Dairyman 61(11): 5153

Sowmya R, Indumathi KP, Arora S, Singh AK (2015) Detection of calcium based neutralizers in milk and milk products by AAS. J Food Sci Technol 52(2):1188-1193

Chamchan, R, Sinchaipanit P, Disnil S, Jittinandana S, Nitithamyong A, On-nom N (2017) Formulation of reduced sugar herbal ice cream using lemongrass or ginger extract. British Food Journal 119(10) 2172-2182

Haratifar S, Corredig M (2014) Interactions between tea catechins and casein micelles and their impact on renneting functionality. Food chemistry 143: 27-32 